\title{
Preliminary Design of Industrial Automation Training Kit Based Real Mobile Plant
}

\author{
Ade Gafar Abdullah ${ }^{\text {a,1 }}$, Dadang Lukman Hakim ${ }^{\mathrm{a}}$, Muhammad Afif Auliya ${ }^{\mathrm{a}}$, \\ Muhammad Akmal Fahrurizal ${ }^{a}$ \\ ${ }^{a}$ Electrical Engineering Education Department, Indonesia University of Education, \\ J1. Dr. Setiabudhi 227, Bandung 40154, West Java, Indonesia \\ 1 ade_gaffar@upi.edu
}

\begin{abstract}
Learning activities in the industrial automation course requires a comprehensive experiment. Expensive lab equipment has implications for the quality of learning. Innovation is needed to produce media that can enhance the skills of learners in the operation and programming of industrial automation devices. This paper introduces the results of a preliminary design of training kit that has a real concept of mobile plant. This equipment was designed to practice basic and advanced logics in the control systems. The device included the real-time control system with open-source software, and also came with the manual book and job sheet. The availability of this device is expected to improve the ability of problem solving in actual control systems.
\end{abstract}

Index Terms - Industrial automation, trainer kit, real mobile plant, real-time control systems.

\section{Introduction}

Industrial automation learning process Indonesia University of Education (UPI) has not been synchronized with technological developments in the industry. Consequently, there was difficulty in adapting to the control equipment that commonly used. Additionally, lab activities still require the ability to explore the capabilities of a comprehensive understanding of basic logic, discrete control handling for complicated cases, and the use of a timer and applicable counter functions.

Problem solving of industrial control systems are not given at sufficient portion in the learning due to a limitation of the learning resources and equipment in the lab. This problem arises due to underdeveloped learning media innovations for industrial automation domain. When we want to increase the lab facilities, we encountered a problem concerning the cost of the equipment. Universities always depend on imported products, which is usually expensive. The lecturers are expected to develop innovative learning to overcome this problem. Through this research, we developed a training kit that is user friendly, low cost, industry-oriented requirements, and portable.

There have been many studies related to the development of industrial training kit or electrical engineering. University of Arizona in collaboration with Motorola has developed simulation software for the management training course [1]. Sungkyunkwan University in Korea developed the hardware to support learning microprocessor, the model training kit to facilitate students in designing a personal microcomputer [2].

In 2002, the Tokyo Metropolitan Institute of Technology has developed a simulator to facilitate students to understand the working principle of a permanent magnet stepper motor. The study recommended that the simulator is very appropriate for use in the learning process of mechatronic design [3]. It has also developed software that advances with a graphical interface for complex interactions in the communication system and database functions. This software was used to create the learning process of automation of manufacturing systems [4].

A virtual laboratory for practical purposes of control system using coupled tank apparatus which has a multi-input multi-output (MIMO) equipped with a simulator of PID control and general state-space and fuzzy logic control was developed by the National University of Singapore [5]. University of Sao Paulo, Brazil, developed an automation system simulator for three-phase electrical measurements integrated with Labview software [6]. Related research is described and discussed in Refs. [7]-[11].

\section{Methods}

The experiment was conducted at the Laboratory of Electronics Industry Department of Electrical Engineering Education UPI. The research activity was focused on design training kit and requirement's identification of devices and materials. This research began with the analysis of the system requirements. A device of training kit was designed to improve skills at the advanced logic in control systems. We designed a plant system that qualifies as a device to practice advanced control and a training kit that has a real mobile plant concept. The device was hence easy to move everywhere so that it could be demonstrated in the classroom.

The development of process control systems technology is associated with the increment of information technology. Performance monitoring of the controller equipment is no longer using a control room that contains a measuring instrument panel, which requires a large room. Real-time control system software has reduced the panel's analogue instruments. Plant performance monitoring is developed by creating a visualization of the controlled equipment. The software often used is e.g. Wonderware InTouch, CX Supervisor and others. With computer network technology, visualization of a plant can communicate with control devices, such as Programmable Logic Controller (PLC). Therefore, the plant can be monitored in realtime, simply by using one computer. The training kit was 
designed by referring to industrial control systems technology trends used the present.

\section{Results and Discussion}

Training kit was designed to develop the capabilities of students in the exercise of advanced logic control. This instructional media such as water level control is equipped with a level sensor, mixer and heater.
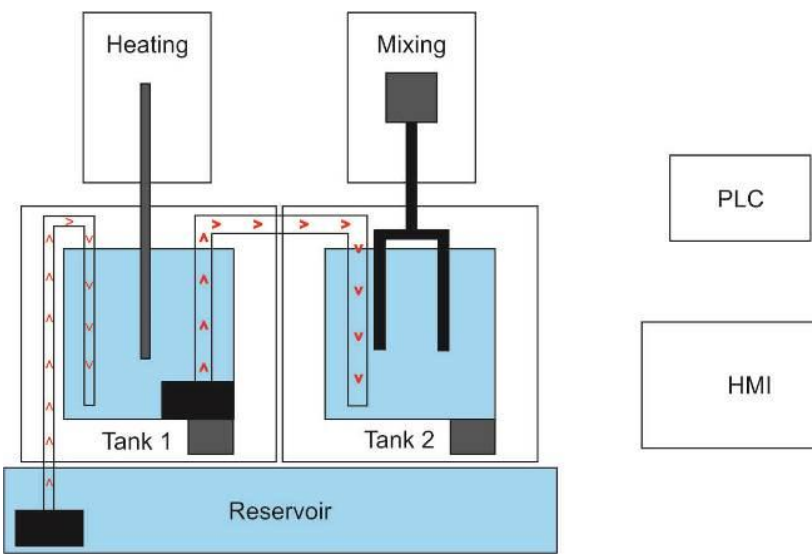

Fig. 1 Design of industrial automation training kit

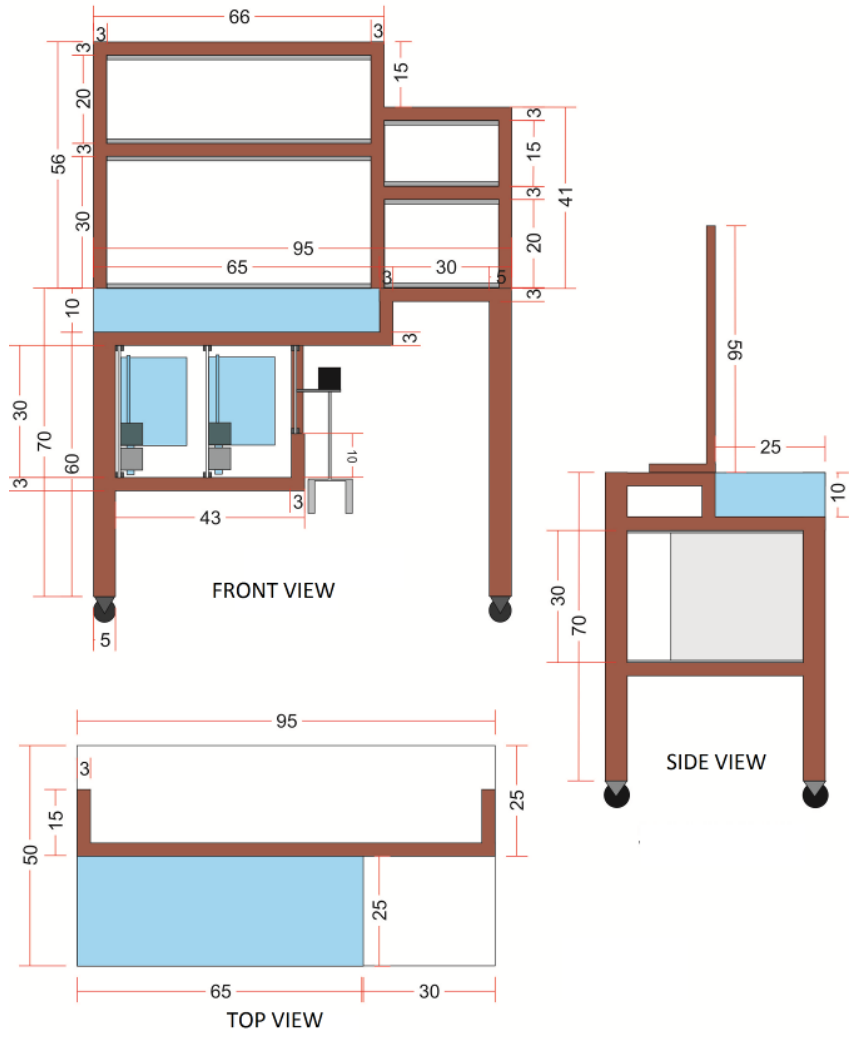

Fig. 2 Complete design automation industry training kit

The training kit consists of a reservoir that functions as a fluid reservoir as shown in Fig. 1. A DC pump, which is placed in the reservoir, works for to move the fluid up to a certain level to the tank 1 . An additional heating device is placed in tank 1 that works to increase the temperature of the fluid according to the set point. Pump in tank 1 serves to move the fluid to the tank 2 . Tank 2 is also equipped with a mixer. The device controller uses PLC, which is equipped with a real-time control system interface or Human Machine Interface (HMI).

The table of training kit consists of three main parts (see Fig. 2), which are a real-plant, the controller, and a device's storage area. The real-plant part is the place where the control occurs, such as mixing and heating process. In this area, every device: tank, mixer, heater and pump were installed. There is grey rail that serves to put the device on the table real-plant. The upper of training kit is used for installing the mixer and heater, while the bottom part is to pair the tank.

The storage of the controller is located right next to the real-plant. The top functions as a place to store the PLC and the bottom serves to implement the HMI device. The lower part is designed to save the real plant modules that were not used by the students. 3D view of the training kit can be visualized in Fig. 3.

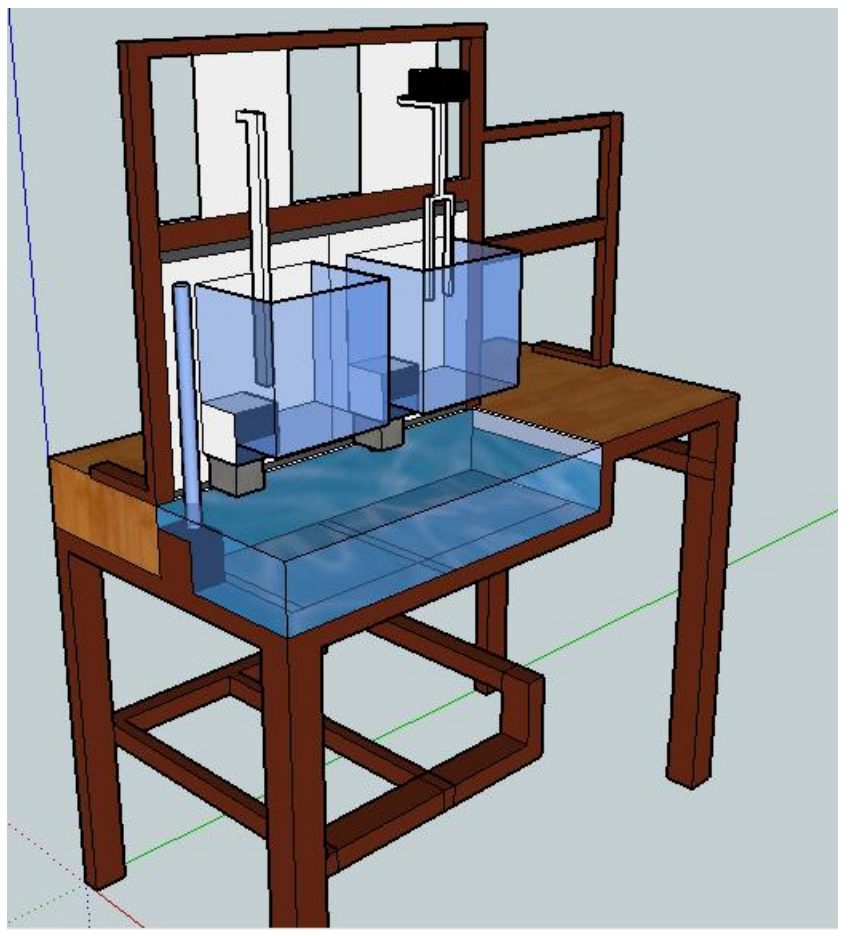

Fig. 3 3D view of the industrial automation training kit

When the design step was completed, further identification devices and materials were required. Referring to the results of the design, the required devices and materials are tabulated in Table 1. This training kit was designed as a practical device for advanced control systems. Therefore, requisite control cases are complicated. Basic rationality for perspective of the possibility in the case is a fluid level control because this case has the potential to be developed into some examples of problem solving.

Implementation of industrial automation learning using this training kit can be realized with the project-based learning. At the beginning of the course, the lecturer can divide students into groups, and each group can discuss to design a job description of control systems that will be developed. Job descriptions of the system should include: process description, ladder diagram and piping diagrams. Furthermore, each group is required to present the results of 
control system design to obtain approval from the lecturers. The next step, students can work on the project on schedule. Lecturers can use authentic assessment instruments during the learning process.

Table 1 List of Devices and Materials for Industrial Automation Training Kit

\begin{tabular}{clcc}
\hline No & \multicolumn{1}{c}{ Devices/ Materials } & Quantity & \\
\hline 1 & HMI Weintek MT6070IH & 1 & pcs \\
2 & DC Pump 24 V & 3 & pcs \\
3 & Power Supply & 1 & pcs \\
4 & PLC Omron CP1E 30 I/O & 1 & pcs \\
5 & Stainless Steel Table & 1 & set \\
6 & Acrylic & 1 & set \\
7 & DC motor for mixer & 1 & pcs \\
8 & Heater & 1 & pcs \\
9 & Probe & 80 & pcs \\
10 & Banana plug & 80 & pcs \\
11 & Solenoid Valve & 2 & pcs \\
12 & Cable & 1 & roll \\
13 & Temperature sensor & 1 & pcs \\
14 & Reed switch magnet sensor & 8 & pcs \\
15 & Aluminum & 6 & m \\
16 & Relay & 4 & pcs \\
17 & Fitting valve & 6 & pcs \\
\hline & & &
\end{tabular}

To guide the implementation of the project, the students can follow this procedure:

1. Understand the physical and logical operation.

2. Identify input, output, state and transition logic conditions from one state to another state.

3. Define the state transition diagram for each condition

4. Create Boolean logic equations of state transition diagrams.

5. Compose the ladder diagrams.

6. Create PLC programs into the ladder diagram with related instruction choice and addresses for input, coil, and output.

One example of the problems in which the control system is used, we can do experiments using the training kit for fluid level control. The description of the process and logic operations is as follows: First, the system is idle. When a start button is pressed, then tank1 is filled by fluid until touches the top of level sensor. Subsequently, the fluid is heated to $100{ }^{\circ} \mathrm{C}$. The next procedure is the removal of fluid from tank1 to tank 2, until the fluid in the tank 1 is empty. Lastly, the fluid is mixed for 20 seconds and then tank 2 is being emptied. Once the whole process is over, the process starts again. When the stop button is pressed, fluid in the tank 1 and 2 are drained and the system returns to the idle condition.

The training kit can lead students to do experiments until the best solution can be obtained. It is also expected to be a solution for universities that have financial limitations because its price is low but its performance is complete.

\section{Conclusions}

Designing of training kit based real mobile plant was intended to support the availability of instructional media in industrial automation learning. Students could use this equipment to encounter the needs of advanced training in process control logic. The concept of a mobile real assembly process was considered to facilitate the acceleration if it was carried into the classroom. After the research was completed, the results could be used as instructional media for industrial automation learning in Polytechnic or University.

\section{Acknowledgment}

The authors would like to thank the Directorate of Higher-Education, Ministry of Education and Culture of the Republic Indonesia, which has provided funding of this research.

\section{References}

[1] J. S. Collofello, "University/industry collaboration in developing a simulation based software project management training course," IEEE Trans. on Education, vol.43, no.4, pp. 389-393, 2000.

[2] J. W. Jeon, "Designing and implementing personal microcomputer," IEEE Trans. on Education, vol. 43, no 4, pp. 426 - 433, 2000.

[3] T. Kikuchi, T. Kenjo, and S. Fukuda, "Developing on educational simulation program for the pm stepping motor," IEEE Trans. on Education, vol. 45, no 1, pp 70-79, 2002.

[4] Y. Chen, "A real time control simulator design for automated manufacturing system using petri nets," Proceeding of the 1991 IEEE International Conference on Robotics and Automation, Sacramento, California, 1991.

[5] C. C. Ko, B. M. Chen, Y. Zhuang, and K. C. Tan, "Development of a web based laboratory for control experiment on a coupled tank apparatus," IEEE Trans. on Education, vol.44, pp. 76-86, 2001.

[6] T. J. Goulart and D. Consonni, "Automated system for measuring electrical three-phase power components," IEEE Trans. on Education, vol.44, no 4, pp. 336-341, 2001.

[7] A. Leva, "A Hands on experimental laboratory for undergraduate course in automatic control," IEEE Trans. on Education, vol. 46, no 2, pp. 263-272, 2003.

[8] F. C Berry and P. S Dipiazza, and S. L. Sauer, "The future of electrical and computer engineering education," IEEE Trans. on Education, vol. 46, no 4, pp. 467 - 476, 2003.

[9] K. Sorao and T. Ueno, "Improvement of accuracy for gauge and elongation control by dynamic process control simulator," Proceeding of the 2004 IEEE International Conference on Control Applications, Taipei, Taiwan, 2004.

[10] P. M. Chen, "An automated feedback system for computer organization project," IEEE Trans. on Education, vol. 47, no. 2, pp. 232-240, 2004.

[11] W. Schaufelberger, "Design and implementation of software for control education," IEEE Trans. on Education, vol. 33, no 3, pp. $291-297,1990$. 